\title{
Relações da dieta ovo-lácteo-vegetariana com o exercício físico e as enzimas antioxidantes superóxido dismutase e catalase
}

\author{
Impact of an ovolactovegetarian diet and \\ strenuous exercise on the antioxidant \\ enzymes superoxide dismutase \\ and catalase
}

Mírian Rocha VÁZQUEZ

Ramon dos Santos EL-BACHÁ2

Carine de Oliveira SOUZA ${ }^{3}$

Tatiana Luzia Borges MACHADO ${ }^{4}$

Ricardo Sereno SILVA 4

José Gerardo Villa VICENTE ${ }^{5}$

Luiz Erlon Araújo RODRIGUES ${ }^{6}$

RE S U M O

\section{Objetivo}

O objetivo deste trabalho foi estudar a influência da dieta ovo-lácteo-vegetariana e do exercício físico extenuante sobre as atividades das enzimas catalase e superóxido dismutase em dez indivíduos masculinos, jovens e saudáveis.

\section{Métodos}

O controle alimentar aplicou-se por quatro meses. Antes disso, foram recolhidas amostras de sangue em estado basal e cinco minutos após o exercício físico extenuante efetuado em esteira rolante. O mesmo procedimento foi aplicado após o controle alimentar.

\footnotetext{
$\overline{1}$ Universidade do Estado da Bahia, Centro de Ciências da Saúde e dos Alimentos, Departamento de Ciências da Vida. R. Silveira Martins, 2555, 41150-000, Cabula, Salvador, BA, Brasil. Correspondência para/Correspondence to: M.R. VÁZQUEZ. E-mail: <mrvazquez@uneb.br>.

2 Universidade do Estado da Bahia, Instituto de Ciências da Saúde. Salvador, BA, Brasil.

${ }^{3}$ Universidade do Estado da Bahia, Nutrição e Saúde. Salvador, BA, Brasil

${ }^{4}$ Universidade Federal da Bahia, Hospital Universitário Prof. Edgar Santos. Salvador, BA, Brasil

5 Universidad de León, Facultad de Ciências de la Actividad Física y del Deporte. León, España

${ }^{6}$ Escola Bahiana de Medicina e Saúde Pública. Salvador, BA, Brasil.
} 
440 | M.R. VÁZQUEZ et al.

\section{Resultados}

Os resultados mostraram que a dieta ovo-lácteo-vegetariana, em condições de repouso, reduziu de forma significativa a atividade da enzima catalase em $18,98 \%(p<0,05)$ e aumentou, também de forma significativa, a atividade da enzima superóxido dismutase em 77,84\% $(p<0,001)$. Depois do exercício físico extenuante, a dieta ovo-lácteo-vegetariana reduziu a atividade da enzima catalase de forma significativa em $26,11 \%(p<0,05)$ e não alterou a atividade da enzima superóxido dismutase.

\section{Conclusão}

Os resultados indicam que tanto as atividades da catalase como da superóxido dismutase são sensíveis a uma dieta ovo-lácteo-vegetariana adequada.

Termos de indexação: Antioxidantes. Dieta vegetariana. Estresse oxidativo. Exercício.

\section{A B S T R A C T}

\section{Objective}

This study aimed to study the influence of an ovolactovegetarian diet and strenuous physical exercise on the activity of the enzymes catalase and superoxide dismutase in 10 young, healthy men whose diet was controlled for four months.

\section{Methods}

Blood samples were collected at baseline and after the four-month period, before strenuous exercise and after 5 minutes of strenuous exercise on a treadmill.

\section{Results}

The results showed that the ovolactovegetarian diet reduced the activity of the enzyme catalase by $18.98 \%$ $(p<0.05)$ and increased the activity of the enzyme superoxide dismutase by $77.84 \%(p<0.001)$ before strenuous exercise. After strenuous exercise, the ovolactovegetarian diet reduced the activity of the enzyme catalase by $26.11 \%(p<0.05)$ and did not affect the activity of the enzyme superoxide dismutase.

\section{Conclusion}

The results indicate that a healthy ovolactovegetarian diet impacts the activity of both enzymes.

Indexing terms: Antioxidant. Diet vegetarian. Oxidative stress. Exercise.

\section{N T R O D U Ç Ã O}

A baixa ocorrência de doenças cardiovasculares, cânceres e outras enfermidades crônicas, observadas nos vegetarianos quando comparados com a população onívora em geral, estão bem documentadas ${ }^{1,2}$. Por outro lado, está descrito que, embora o exercício físico, prescrito como terapia para muitas dessas doenças, quando em excesso, produz grandes adaptações metabólicas, estruturais e funcionais, além do aumento da produção de espécies reativas de oxigênio que podem levar ao estresse oxidativo ${ }^{3-5}$. Atribui-se ao estresse oxidativo não somente a fadiga muscular, mas também a gênese de diversas patologias como as cardiovasculares e vários tipos de cânceres, além da aceleração do envelhecimento ${ }^{6-9}$. O estresse oxidativo ocorre, entre outras causas, quando o sistema de defesa antioxidante não é capaz de neutralizar a ação das espécies reativas de oxigênio ${ }^{5}$, seja por sua depleção ou por sua deficiência. Como consequência, os sistemas biológicos expostos ao estresse oxidativo podem sofrer citotoxicidade, mutações e aberrações cromossômicas, entre outros efeitos $3-5,8,10,11$. Para manter a homeostase oxidativa, o organismo desenvolve mecanismos de defesa antioxidantes endógenos, tais como as enzimas catalase (EC 1.11.1.6), superóxido dismutase (EC 1.15.1.1) e glutation peroxidase (EC 1.11.1.9), além de antioxidantes exógenos de natureza vitamínica ( $\beta$-caroteno, $\alpha$-tocoferol e ácido ascórbico), mineral (zinco, selênio e cobre) e bioflavonoides existentes nos alimentos, sobretudo de origem vegetal (frutas, 
hortaliças, cereais e leguminosas) ${ }^{12-14}$. Resultados epidemiológicos e experimentais indicam que dietas equilibradas podem reduzir o estresse oxidativo ${ }^{15}$. Como consequência do Exercício Físico Extenuante (EFE), tem sido observada uma redução na concentração da vitamina $\mathrm{E}$ nas membranas celulares, assim como aumento da atividade da catalase em eritrócitos humanos, evidenciando, de forma indireta, indução de estresse oxidativo $^{5,15}$.

Este trabalho teve como objetivo verificar o efeito da dieta Ovo-Lácteo-Vegetariana (DOL) e do EFE sobre as atividades das enzimas Catalase (CAT) e Superóxido Dismutase (SOD) em indivíduos jovens e saudáveis.

\section{M É T O D O S}

Foram selecionados dez indivíduos masculinos, saudáveis, não fumantes, não etilistas e não sedentários. Todos eram estudantes com idades compreendidas entre 18 e 20 anos, matriculados no primeiro ano do Instituto Adventista do Nordeste (IAENE), residentes em sistema de internato. Por motivos religiosos, a alimentação quotidianamente servida no IAENE era ovo-lácteo-vegetariana. Após a autorização por escrito para participar do trabalho e a aprovação pelo Conselho de Ética da Escola Bahiana de Medicina e Saúde Pública, sob protocolo no 043/2000, de 5 de junho de 2000, os indivíduos foram submetidos às análises clínicas e ao teste de ergoespirometria de acordo com o protocolo de Bruce para determinar o $\mathrm{VO}_{2 \text { máx }}$.

Antes do início do programa alimentar ovo-lácteo-vegetariano, todos os indivíduos realizaram separadamente um teste de esforço máximo numa esteira rolante, até a exaustão. A partir daí, determinou-se a intensidade do exercício em que eles se encontravam a $75 \%$ do seu consumo máximo de oxigênio. Determinado esse parâmetro, os participantes realizaram um teste de EFE até a exaustão. Recolheram-se amostras de sangue antes do exercício e dez minutos após seu término, para avaliar as atividades da CAT e SOD.
Eles não tomaram bebidas alcoólicas nem outro tipo de droga durante a semana que precedeu os testes.

Realizou-se o controle alimentar durante quatro meses seguidos e, ao final, os participantes foram submetidos novamente ao EFE até a exaustão, após o quê foram recolhidas amostras de sangue. O status antioxidante foi avaliado através das atividades da SOD e CAT.

\section{Critério de seleção da amostra}

Foram selecionados inicialmente 31 voluntários, sedentários (esporte regular máximo de uma vez por semana em sessões com menos de 30 minutos), todos residentes no Instituto, onde também se alimentavam. Cada um deles foi submetido a um inquérito de hábitos de vida (horas de sono, prática de atividade física, consumo de drogas, medicamentos e álcool), dados clínicos (hipertensão, diabetes, dislipidemia, parasitoses) e nutricionais (horário e fracionamento habitual das refeições, preferências e aversões alimentares). Considerou-se como critério de exclusão o sobrepeso (Calculado pelo Índice de Massa Corporal - IMC-kg/cm², 19 $\leq \mathrm{MC} \leq 24)$, a prática regular de exercícios físicos, o consumo de drogas, medicamentos e álcool, além da presença de qualquer enfermidade relacionada com os dados clínicos. Também se excluíram aqueles indivíduos que não aceitaram de bom grado submeter-se às condições experimentais. Depois da primeira seleção, restaram 18 indivíduos. Após a realização das análises clínicas (tensão arterial, frequência cardíaca), bioquímicas (glicemia, colesterol total e frações, ácido úrico), sumário de urina e parasitológico de fezes, antes e depois do controle alimentar, apenas 10 indivíduos foram selecionados e finalizaram o estudo.

Antes de iniciar a DOL, os indivíduos foram submetidos a avaliação nutricional que incluiu: anamnese sobre os alimentos ingeridos, dados bioquímicos, exames clínicos, antecedentes médicos e familiares, além dos dados antropométricos e psicossociais. Para avaliar a quantidade 
dos alimentos ingeridos, uma semana antes e depois do controle alimentar, utilizou-se o método do resto-ingesta ${ }^{16}$. A necessidade energética total, assim como o consumo diário de vitaminas e minerais foram calculados de acordo com a Recommended Dietary Allowances (RDA) da Food and Nutrition Board National Research Council, $1998{ }^{17}$. Para o cálculo da ingestão diária de proteínas, lipídeos, carboidratos e fibras, utilizaram-se as recomendações da Sociedade Brasileira de Alimentação e Nutrição ${ }^{18}$. Para quantificar o consumo alimentar diário, foram utilizados recipientes graduados e adaptados às medidas caseiras $^{19}$.

Todos os indivíduos foram previamente treinados sobre o método do controle nutricional e o comportamento alimentar que adotariam durante o estudo. Foram feitos os ajustes necessários aos cardápios diários e instruíram-se os funcionários do restaurante para prepararem e servirem com rigor as rações correspondentes. Estabele- ceram-se os padrões e as graduações dos utensílios para a distribuição dos alimentos (copos, xícaras e conchas graduados) para assim definir as quantidades e as medidas a administrar-se. Separou-se a distribuição das refeições (restaurante reservado para os indivíduos com dieta), o que possibilitou uma supervisão eficaz. Assegurou-se a quantidade ingerida, pesando-se os restos de comida, ossos e cascas que sobravam no prato, mediante o método do resto-ingesta.

A avaliação do consumo diário médio de nutrientes realizou-se com o software Virtual Nutri versão 1 e as tabelas de composição química dos alimentos 20 .

\section{Cardápios básicos da dieta ovo-lácteo-vegetariana}

Desjejum: Nescau ${ }^{\circledR}$ ou farinha láctea, leite integral, iogurte, açúcar mascavo, pão, biscoitos,

Tabela 1. Aporte semanal de alimentos durante o consumo das dietas livre e ovo-lácteo-vegetariana.

\begin{tabular}{|c|c|c|c|c|c|c|}
\hline & \multicolumn{2}{|c|}{ Dieta livre (DL) } & \multicolumn{2}{|c|}{ Dieta ovo-lácteo-vegetariana (DOL) } & \multirow{2}{*}{$\% \Delta$} & \multirow{2}{*}{$p$} \\
\hline & $\mathrm{M}$ & DP & $\mathrm{M}$ & DP & & \\
\hline Leguminosas cozidas (g) & 2474,15 & 130,83 & 3071,18 & 260,82 & 24,13 & ** \\
\hline Leite integral $(\mathrm{mL})$ & 1261,47 & 45,22 & 1266,96 & 131,53 & 0,43 & n.s. \\
\hline Queijo (g) & 114,52 & 16,52 & 216,79 & 27,44 & 89,30 & * \\
\hline Cereais (g) & 2444,12 & 90,65 & 2519,86 & 262,71 & 3,10 & n.s. \\
\hline Carne bovina (g) & 588,16 & 72,36 & & & & \\
\hline Frango $(g)$ & 421,82 & 39,90 & & & & \\
\hline Pescado (g) & 261,12 & 9,35 & & & & \\
\hline Ovos (g) & 157,20 & 34,70 & 980,00 & 26,88 & 523,41 & *** \\
\hline Hortaliças (g) & 321,80 & 26,16 & 506,00 & 12,60 & 57,24 & ** \\
\hline Frutas $(\mathrm{g})$ & 1141,56 & 152,04 & 2856,42 & 109,41 & 150,22 & ** \\
\hline Farinha de mandioca (g) & 322,07 & 19,81 & 147,00 & 22,12 & $-54,36$ & * \\
\hline Açúcar e doces (g) & 280,77 & 22,61 & 263,55 & 24,15 & $-6,13$ & n.s. \\
\hline Sucos $(m \mathrm{~L})$ & 856,98 & 25,00 & 4284,07 & 70,84 & 399,90 & *** \\
\hline Refrigerantes $(\mathrm{mL})$ & 2000,00 & 0,60 & & & & \\
\hline Azeite de oliva $(\mathrm{mL})$ & 45,29 & 4,48 & 107,52 & 83,72 & 137,40 & * \\
\hline Azeite de dendê (mL) & 23,45 & 1,29 & & & & \\
\hline Óleo de soja (mL) & 146,86 & 52,43 & 126,07 & 37,52 & $-14,16$ & n.s. \\
\hline Pastelaria frita (g) & 432,00 & 12,16 & & & & \\
\hline Manteiga (g) & 105,56 & 82,67 & 66,04 & 22,61 & $-37,47$ & n.s. \\
\hline Leite de coco (g) & 62,76 & 3,52 & 42,76 & 14,20 & $-31,87$ & * \\
\hline Soja (g) & & & 151,05 & 33,51 & & \\
\hline Gluten (g) & & & 40,64 & 2,66 & & \\
\hline logurte (g) & & & 1624,63 & 43,96 & & \\
\hline
\end{tabular}

M: média; DP: desvio-padrão; \% $\Delta$ : variação em percentagem; níveis de significância estatística das diferenças: ${ }^{*} p<0,05 ;{ }^{* *} p<0,01 ;{ }^{* * *} p<0,001 ;$ n.s.: não significativa. 
manteiga ou marmelada, ovos, queijo caseiro, frutas, batata-doce ou aipim, inhame ou bananas fritas com açúcar e canela, cuscuz e mingaus em dias alternados.

Almoço: Salada crua e cozida, pratos à base de glúten (duas vezes por semana), pratos à base de soja texturizada (uma vez por semana), pratos à base de ovos (quatro vezes por semana), arroz ou massa, feijão branco, lentilha, grão de bico ou ervilha (em dias alternados), suco de fruta com açúcar.

Sobremesa: Frutas (cinco vezes por semana), doces (duas vezes por semana).
Jantar: Sopa com massa, hortaliças e leguminosas, iogurte, pastas italianas, pão (diversos), queijo, frutas, sucos de frutas, açúcar.

\section{Prova de esforço}

Cinco minutos antes de começar a prova, foram puncionados $5 \mathrm{~mL}$ de sangue. A prova foi realizada em uma esteira rolante em posição horizontal, iniciando-se a uma velocidade de $6 \mathrm{~km} / \mathrm{h}$ e aumentando-a gradualmente a uma taxa de $1 \mathrm{~km} / \mathrm{h}$ por minuto, até que os indivíduos alcançassem $80 \%$ da frequência cardíaca máxima

Tabela 2. Aporte médio diário de energia, nutrientes e fibras durante o consumo das dietas livre e ovo-lácteo-vegetariana.

\begin{tabular}{|c|c|c|c|c|c|c|}
\hline & \multicolumn{2}{|c|}{ Dieta livre (DL) } & \multicolumn{2}{|c|}{ Dieta ovo-lácteo-vegetariana (DOL) } & \multirow{2}{*}{$\% \Delta$} & \multirow{2}{*}{$p$} \\
\hline & $\mathrm{M}$ & DP & $\mathrm{M}$ & DP & & \\
\hline Energia (kcal) & 3364,36 & 842,08 & 2818,17 & 381,00 & $-16,23$ & n.s. \\
\hline Carboidratos simples (g) & 134,28 & 55,70 & 55,24 & 24,77 & $-58,86$ & * \\
\hline Carboidratos complexos (g) & 354,29 & 64,74 & 424,00 & 54,87 & 19,68 & * \\
\hline Proteína de baixo valor biol (g) & 42,46 & 16,77 & 55,38 & 14,77 & 30,43 & * \\
\hline Proteína de alto valor biol (g) & 60,86 & 29,17 & 24,23 & 11,23 & $-60,19$ & ** \\
\hline Lipídeos saturados (g) & 52,74 & 12,56 & 18,78 & 2,54 & $-64,39$ & ** \\
\hline Lipídeos poli-insaturados (g) & 26,16 & 6,54 & 25,67 & 3,48 & $-1,87$ & n.s. \\
\hline Lipídeos monoinsaturados (g) & 18,51 & 5,38 & 25,98 & 3,51 & 40,36 & * \\
\hline Fibras alimentar (g) & 14,32 & 5,23 & 22,32 & 9,20 & 55,87 & ** \\
\hline Colesterol (mg) & 471,00 & 30,02 & 120,32 & 32,70 & $-74,45$ & *** \\
\hline Tiamina - $B_{1}(m g)$ & 2,57 & 0,24 & 2,72 & 0,51 & 5,84 & ** \\
\hline Riboflavina - $B_{2}(\mathrm{mg})$ & 2,53 & 0,41 & 2,55 & 0,40 & 0,79 & n.s. \\
\hline Vitamina $B_{6}$ - piridoxina $(\mathrm{mg})$ & 2,75 & 0,31 & 1,91 & 0,34 & $-30,55$ & n.s. \\
\hline Vitamina $B_{12}$ - cobalamina $(\mu \mathrm{g})$ & 7,56 & 0,94 & 4,55 & 1,11 & $-39,81$ & * \\
\hline Niacina $-B_{3}(m g)$ & 36,16 & 6,08 & 20,98 & 3,63 & $-41,98$ & * \\
\hline Folato - $B_{9}(\mu \mathrm{g})$ & 266,21 & 41,83 & 445,06 & 83,76 & 67,18 & ** \\
\hline Ac. Ascórbico - C (mg) & 76,10 & 19,11 & 171,03 & 94,36 & 124,74 & n.s. \\
\hline
\end{tabular}

M: média; DP: desvio-padrão; biol: biológico; AC: ácido; \% $\Delta$ : variação em percentagem; níveis de significância estatística das diferenças: " $p<0,05$; ${ }^{* *} p<0,01 ;{ }^{* * *} p<0,001 ;$ n.s.: não significativa.

Tabela 3. Aporte médio diário de minerais durante o consumo das dietas livre e ovo-lácteo-vegetariana

\begin{tabular}{|c|c|c|c|c|c|c|}
\hline & \multicolumn{2}{|c|}{ Dieta livre (DL) } & \multicolumn{2}{|c|}{ Dieta ovo-lácteo-vegetariana (DOL) } & \multirow{2}{*}{$\% \Delta$} & \multirow{2}{*}{$p$} \\
\hline & $\mathrm{M}$ & DP & $\mathrm{M}$ & DP & & \\
\hline Cálcio (mg) & 926,05 & 231,61 & 1868,99 & 147,25 & 101,82 & *** \\
\hline Magnésio (mg) & 274,49 & 61,04 & 306,64 & 77,25 & 11,71 & n.s. \\
\hline Zinco (mg) & 18,34 & 2,71 & 11,60 & 1,15 & $-36,75$ & * \\
\hline Ferro (mg) & 19,50 & 3,90 & 17,59 & 2,21 & $-9,79$ & n.s. \\
\hline Selênio $(\mu \mathrm{g})$ & 113,55 & 42,20 & 106,28 & 20,67 & $-6,40$ & n.s. \\
\hline
\end{tabular}

M: média; DP: desvio-padrão; \% $\%$ : variação em percentagem.

Níveis de significância estatística das diferenças: ${ }^{*} p<0,05 ;{ }^{* *} p<0,01 ;{ }^{* * *} p<0,001$; n.s.: não significativa. 
$\left(F C_{\text {max }}\right)$. A partir desse ponto, manteve-se a velocidade constante até a exaustão, determinada por dor muscular ou articular, ou por fadiga para continuar o exercício. Depois da recuperação, a $6 \mathrm{~km} / \mathrm{h}$ durante 5 minutos, e do descanso de mais 5 minutos, foram recolhidas $5 \mathrm{~mL}$ de sangue.

\section{Método para quantificar a atividade da SOD}

A extração da SOD realizou-se mediante as hemólises dos eritrócitos lavados e centrifugados duas vezes a $900 \mathrm{~g}$ com solução a 0,9\% de cloreto de sódio e ressuspensos em água destilada. A partir da fase aquosa, quantificaram-se as proteínas pelo método de Lowry et al. ${ }^{21}$. A análise da SOD nos eritrócitos realizou-se pelo método indireto, utilizando a xantina e a xantina oxidase $\left(\mathrm{SIGMA}^{\circledR}\right)$, como sistema produtor de oxigênio nascente. A atividade da SOD foi calculada espectrofotometricamente $(\mathrm{nm})$, mediante a inibição da velocidade de formação do radical superóxido que reduz o citocromo C (SIGMA $\left.{ }^{\circledR}\right)$, uma vez que a SOD compete pelos radicais superóxidos ${ }^{22}$. Uma unidade SOD $(U)$ corresponde à quantidade de enzima capaz de inibir a redução do citocromo c em 50,0\% no sistema acoplado com xantina oxi-dase em $\mathrm{pH} 7,8$ e a $25^{\circ} \mathrm{C}$ em um volume de reação de $3 \mathrm{~mL}$.

\section{Método para quantificar a atividade da CAT}

O hemolisado foi preparado com aproximadamente $5 \mathrm{~g}$ de hemoglobina por $100 \mathrm{~mL}$, e a atividade catalásica foi determinada pela incubação de $2 \mathrm{~mL}$ do hemolisado com $1 \mathrm{~mL}$ de peróxido de hidrogênio $30 \mathrm{mM}$ a $20^{\circ} \mathrm{C}$. A absorbância do sistema foi medida espectrofotometricamente em 240nm nos tempos de zero, 10, 20 e 30 segundos. A atividade catalásica foi expressa em $\mathrm{mMol} . \mathrm{mgHB}^{-1} \cdot \mathrm{s}^{-1}$.

\section{Dados estatísticos}

Para analisar as diferenças das variáveis antes e depois da dieta e antes e depois do EFE, utilizou-se o teste não paramétrico de Wilcoxon para amostras pareadas. A análise estatística foi realizada mediante o programa estatístico Statistic- $V$ 4.5 para o sistema operacional Windows- $X P^{\circledR}$.

\section{RES ULT A DOS}

\section{Características das dietas}

A Tabela 1 mostra o aporte médio semanal dos alimentos consumidos antes e depois do controle alimentar, ou seja, com Dieta Livre (DL) e com DOL. Algumas alterações foram feitas para adequar a dieta às recomendações da Sociedade Brasileira de Alimentação e Nutrição (SBAN). Houve aumento significativo do consumo de leguminosas (principalmente a inclusão da soja), glúten, iogurte, queijo, ovos, hortaliças, frutas e sucos. Por outro lado, houve redução de farinha de mandioca e óleo de soja, e exclusão de carnes, pescados, refrigerantes, salgadinhos fritos e embutidos.

Ao comparar a ingestão diária de nutrientes das dietas DOL e DL (Tabela 2), observam-se as seguintes modificações: redução significativa $(p<0,05)$ de carboidratos simples $(-58,86 \%)$, proteínas de alto valor biológico $(-60,18 \%)$, lipídeos saturados (-64,39\%) e colesterol exógeno $(-53,22 \%)$; redução significativa das vitaminas piridoxina $(-30,54 \%)$ e cobalamina $(-39,81 \%)$, de minerais e particularmente de zinco $(-36,75 \%)$. Observam-se também aumentos significativos de carboidratos complexos (19,67\%), proteínas de baixo valor biológico $(30,43 \%)$, lipídeos monoinsaturados $(40,35)$, fibras alimentares $(55,86 \%)$ e folato $(67,18 \%)$. Quanto aos minerais, observa-se aumento significativo $(p<0,001)$ de cálcio $101,82 \%$. O ferro e o selênio sofreram redução, mas de forma não significativa.

\section{Influência da dieta sobre as atividades da CAT e SOD}

A Figura 1 mostra a influência do EFE, antes e depois da DOL, sobre a atividade da enzima 
antioxidante CAT. Antes do Controle Alimentar (DL), observou-se uma elevação significativa $(p<0,05)$ de $20,84 \%$ da atividade da CAT. Depois do DL e do EFE, com o mesmo protocolo, a atividade da CAT incrementou também, mas de forma não significativa, em 13,58\%. Isso significa que o

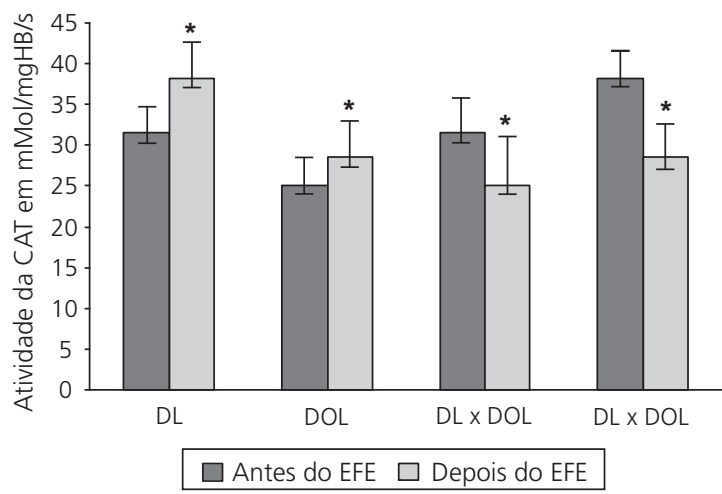

Figura 1. Modificações na atividade da catalase eritrocitária humana em consequência do exercício físico extenuante, antes da dieta livre e depois da dieta ovo-lácteo-vegetariana. Cachoeira (BA), 2002.

Nota: Valores médios mais os desvios-padrões e nível de significância: * $p>0,05$.

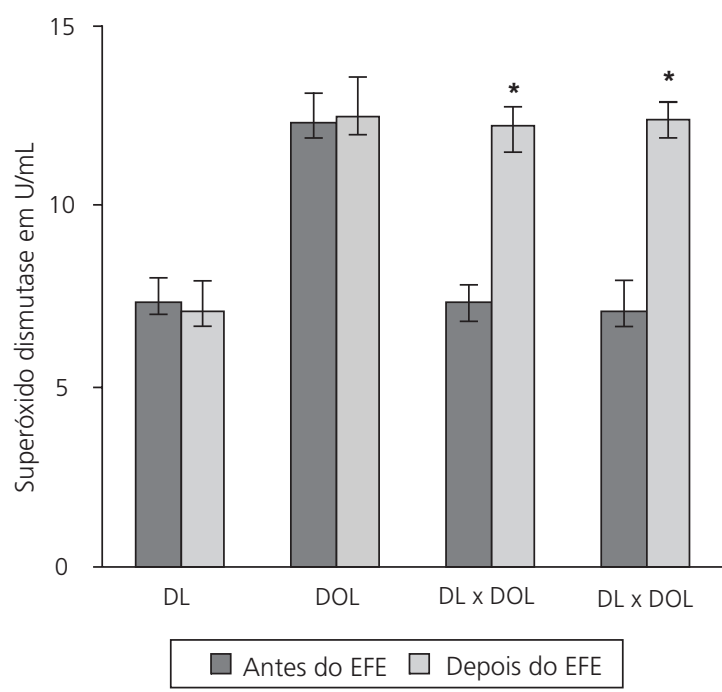

Figura 2. Modificações na atividade da superóxido dismutase de eritrócitos humanos em consequência do exercício físico extenuante, antes da dieta livre e depois da dieta ovo-lácteo-vegetariana. Cachoeira, (BA), 2002.

Nota: Valores médios e desvios-padrões, nível de significância: " $p<0,05$.
EFE induz aumento da atividade catalásica, independentemente da dieta. Mas, quando se compara o aumento da atividade catalásica induzida pelo EFE, antes e depois da DOL, observa-se uma diminuição não significativa, de 26,12\%. Esse fato sugere que a CAT é um indicador de estresse oxidativo e que a DOL interfere no aumento da atividade enzimática, induzida pelo EFE. Quando se comparam as atividades da CAT, antes e depois do controle alimentar, observa-se uma redução de forma significativa de $-20,47 \%(p<0,05)$.

A Figura 2 mostra que a SOD não se modificou em consequência do EFE, tanto antes como depois do controle alimentar; no entanto, constata-se que a atividade da SOD aumentou de forma significativa em $77 \%$ após a DOL.

\section{I S C U S S Ã O}

A atividade da catalase medida em eritrócitos tem sido empregada como um dos indicadores de status oxidativo em seres humanos ${ }^{23-25}$. Os eritrócitos são sensíveis a lesões oxidativas em função do alto conteúdo de ácidos graxos poli-insaturados em suas membranas e das altas concentrações intracelulares de oxigênio e hemoglobina, que são promotores potenciais de processos oxidativos $^{24}$. Neste trabalho, constatou-se que o EFE, antes do controle alimentar, produziu uma elevação significativa $(p<0,05)$ de $20,84 \%$ da atividade da CAT. No entanto, depois da DOL, e antes do EFE, a atividade da CAT incrementou também, mas de forma não significativa em $13,58 \%$. Isso talvez signifique que o EFE induz um aumento da atividade catalásica, independentemente da dieta. Mas, quando se compara o aumento da atividade catalásica induzida pelo EFE, antes e depois da DOL, observa-se uma diminuição não significativa de $26,12 \%$. A DOL minimizou os efeitos do EFE sobre a atividade da enzima.

O exercício pode elevar a atividade catalásica, e supõe-se que a produção do radical supe- 
róxido, durante o EFE, seja o fator responsável por essa elevação. $O$ ânion superóxido reage com o ferro contido nessa enzima, mantendo-o na forma ativa de Fe III (Tauler et al..25). Quando se compara a atividade da CAT, antes e depois do controle alimentar, observa-se uma redução de $-20,47 \%$, de forma significativa $(p<0,05)$. A DOL reduziu a atividade da CAT diante de um EFE, o que pode ser atribuído ao aumento do consumo de hortaliças, frutas e sucos, além de outros componentes da dieta. A DOL exerceu um papel protetor, ou pelo menos, redutor do estresse oxidativo, induzido pelo EFE. A dieta pode interferir no status oxidativo, uma vez que nos alimentos encontram-se substâncias antioxidantes como as vitaminas $A, C, E$, carotenoides, fenóis, selênio, zinco, e pro-oxidantes, como ferro, ácidos graxos poli-insaturados, entre outros ${ }^{26}$.

Embora neste trabalho a DOL tenha incrementado o consumo de vitamina C (Tabela 2) e reduzido o zinco (-36.75\%), o ferro e selênio, mesmo que de forma não significativa (Tabela 3), não se pode atribuir, de forma direta, algum tipo de interferência da dieta sobre o status oxidativo a uma ou outra substância isoladamente, uma vez que elas interagem e atuam em bloco. Por exemplo, a vitamina $A$ e os carotenoides são antioxidantes altamente eficientes principalmente na inativação do oxigênio singlet ${ }^{10}$; a vitamina $\mathrm{E}$ estabiliza as membranas biológicas, protege a degradação da vitamina A e de outros retinoides, impede a peroxidação de sua cadeia carbônica insaturada, aumenta a eficiência vitamínica e antioxidante, melhorando as condições de armazenamento no organismo ${ }^{26}$. As necessidades de vitamina $\mathrm{E}$ aumentam com a ingestão aumentada de ácidos graxos poli-insaturados. A vitamina $C$ pode eliminar superóxidos e atuar como redutor cooperativista na regeneração da vitamina E; também a regeneração da vitamina $C$ no sistema redox depende da glutation redutase e reduz o $\mathrm{Fe}^{3+}$ a Fe ${ }^{2+}$ que, por sua vez, na presença de $\mathrm{H}_{2} \mathrm{O}_{2}$ pode estimular a formação do Radical Hidroxil $\left(\mathrm{HO}^{*}\right)^{15}$. Os polifenóis podem sequestrar radicais livres e quelar cátions divalentes como o $\mathrm{Fe}^{2+}$, agindo tanto na etapa de iniciação como na propagação de processos oxidativos ${ }^{13}$. O selênio é utilizado como cofator da enzima antioxidante glutation peroxidase; o zinco juntamente com o cobre faz parte da enzima superoxido dismutase citosólica (Cu-ZnSOD), e o manganês é o cofator metálico da superoxido dismutase na matriz mitocondrial (Mn-ZnSOD). Entre as diversas classes de substâncias antioxidantes de ocorrência natural, os compostos fenólicos têm recebido muita atenção nos últimos anos, sobretudo por inibirem a peroxidação lipídica ${ }^{13}$. A interação entre os micronutrientes indica que a ingestão marginal de um desses antioxidantes pode provocar a redução na bioatividade de outro micronutriente essencial, embora aquele seja consumido nos níveis recomendados $^{12}$.

Uma dieta equilibrada aporta ao mesmo tempo antioxidantes de natureza vitamínica, mineral, carotenoides e fenóis, que, de forma interativa, podem aumentar a capacidade antioxidante do organismo e reduzir a atividade da CAT ${ }^{15}$. Segundo Stachowska et al. ${ }^{23}$, a administração de dieta tipo mediterrâneo por 6 meses reduziu significativamente a atividade da catalase em eritrócitos de pacientes submetidos a transplante renal.

Os resultados apresentados neste trabalho evidenciam que a dieta ovo-lácteo-vegetariana, por si só, não interfere na atividade da catalase na condição basal. Isso sugere a não formação de peróxido de hidrogênio suficiente para depletar essa enzima nas condições propostas no estudo. Contudo, a atividade da SOD se mostra sensível ao hábito alimentar e, ao contrário da CAT, não sofreu influência do EFE. Como a SOD é a principal enzima responsável pela detoxificação do ânion superóxido, e como ele é importante para iniciar a reação do estresse oxidativo, pode-se inferir que a DOL é mais eficiente contra o estresse oxidativo que a dieta DL. Isso porque a manutenção do status antioxidante é feita através de mecanismos enzimáticos e não enzimáticos, enquanto neste estudo apenas dois parâmetros foram avaliados (SOD e CAT). Assim sendo, são necessários outros estudos que permitam um melhor entendimen- 
to dos efeitos globais da ingestão da dieta ovo-lácteo-vegetariana e do exercício físico extenuante sobre o estresse oxidativo.

\section{O N CLUS Ã O}

As atividades das enzimas CAT e SOD sofreram influência da DOL em condições de repouso. Houve redução da atividade da CAT, assim como aumento significativo da atividade da SOD. Para a detecção de possíveis efeitos relacionados ao dano oxidativo, seria necessária a utilização de técnicas mais sensíveis que as utilizadas neste trabalho. No entanto, pode-se concluir que a prática de EFE incrementa a atividade da CAT sem modificar a da SOD. Depois de quatro meses de DOL, o EFE induziu uma menor elevação da atividade da CAT. Esses dados sugerem a presença de compostos antioxidantes componentes da DOL, que minimizam os efeitos do EFE sobre a atividade de CAT.

\section{A GRADECIMENTOS}

Ao Laboratório de Pesquisas Básicas da Escola Bahiana de Medicina e Saúde Pública - FBDC e ao Laboratório de Neuroquímica e Biologia Celular do Instituto de Ciências da Saúde da Universidade Federal da Bahia - Salvador, onde foi realizada parte dos experimentos.

\section{COLABORADORES}

Todos os autores participaram de todas as fases da pesquisa e redação do artigo.

\section{REFERÊ NCIAS}

1. Cannon G. Food, nutrition and the prevention of cancer: a global perspective. Washington (DC): American Institute for Cancer Research; 1997.

2. Kushi LH, Meyer KA, Jacobs DR. Cereals, legumes and chronic disease risk: evidence from epidemiologic studies. Am J Clin Nutr. 1999; 70: 451-9.

3. Supinnski G. Free radical induced respiratory muscle dysfunction. Mol Cell Biochem. 1998; 179:99-110.
4. Powers SK, Lennon SL. Analyses of cellular responses to free radicals: focus on exercise and skeletal muscle. Proc Nutr Soc. 1999; 58:1025-8.

5. Subudhi AW, Scott LD, Kipp RW, Wayne EA. Antioxidant status and oxidative stress in elite alpine ski racers. Int J Sport Nutr Exerc Metab. 2001; 11: 32-9.

6. Almar M, Villa JG, Cuevas MJ, Rodríguez-Marroyo JA, Avila C, Gonzalez-Gallego J. Urinary levels of 8-hydroxydeoxyguanosine as a marker of oxidative damage in road cycling. Free Rad Res. 2001; 22:1-7.

7. Kostka T, Bonnefoy M, Arsac L, Berthouze S, Belli A, Lacour JR. Habitual physical activity and peak anaerobic power in elderly women. Eur J Appl Physiol 1997; 76:81-9.

8. Volkovová K, Dusinská M, Collins AR. From oxidative DNA damage to molecular epidemiology. J Appl Biomed. 2006; 4:39-43.

9. Divisi D, Tommaso SD, Salvemini S, Garramone M, Cresci R. Diet and cancer. Acta Biomed. 2006; 77: 118-23.

10. Aruoma OI. Free radicals, oxidative stress and antioxidants in human health and disease. J Am Oil Chem Soc. 1998; 75:199-213.

11. Naoum PC. Radicales libres y daños eritrocitarios. Rev Hematol 2001; 1:150-72.

12. Vannucchi $H$, Moreira EAM, Ferreira DC, Junqueira Franco MVM, Bernardes MM, et al. Papel dos nutrientes na peroxidação lipídica. Med Rib Preto. 1998; 31:31-8.

13. Moure A, Cruz JM, Franco D, Dominguez JM, Sinero $J$, Dominguez $\mathrm{H}$, et al. Natural antioxidants from residual source. Food Chem. 2001; 72:145-71.

14. Skjelbred FC, Saebo M, Hjartaker A, Grotmol T, Hansteen I, Tveit KM, et al. Meat, vegetables and genetic polymorphisms and the risk of colorectal carcinomas and adenomas. BMC Cancer. 2007; 7: 228-239.

15. Vázquez RM, El-Bachá SR, Ordas CA, Ribeiro $B E$, Vicente VJG, Rodrigues LEA. Dieta afro-bahiana, estrés oxidativo y ejercicio físico. Rev Nutr. 2006; 19(6):673-83. doi: 10/590/S1415-527320060006 00004

16. Mahan LK, Arlin MT. Krause's, food, nutrition and diet therapy. Washington (DC): WB. Saunders; 1998. p.289-350.

17. Food and Nutrition Board, National Research Council. Recommended dietary allowances. 10 ed. Washington (DC); National Academy Press; 1998.

18. Vannucchi H, Menezes EW, Campana A, Lajolo FC. Aplicações das recomendações nutricionais adaptadas à população brasileira. Cad Nutr SBAN. 1990; 2:155. 
19. Pinheiro BV, Lacerda EM, Benzecry EH. Tabela para avaliação do consumo alimentar com medidas caseiras. $4^{a}$ ed. Rio de Janeiro: Atheneu; 1998.

20. Philippi ST. Tabela de composição de alimentos: suporte para decisão nutricional. $2^{a}$ ed. São Paulo: Colonário; 2002.

21. Lowry EH, Rosenbrough NJ, Farr LL, Randdall RJ. Protein measurement with Folin phenol reagent. J Biol Chem. 1951; 193(1):265-75.

22. Abelson JN, Simon MI. Methods in enzymology. Oxygen radicals and antioxidants. San Francisco (CA): Academic Press; 1984. p.101-4.

23. Stachowska E, Wesolowska T, Olszewska M, Safranow K, Millo B, Domanski L, et al. Elements of mediterranean diet improve oxidative status in blood of kidney graft recipients. Br J Nutr. 2005; 93(3):345-52.
24. Jung UJ, Kim HJ, Lee JS, Lee MK, Kim HO, Park EJ, et al. Naringin supplementation lowers plasma lipids and enhances erythrocyte antioxidant enzyme activities in hypercholesterolemia subjects. Clin Nutr. 2003; 22(6):561-8.

25. Tauler P, Aguilo A, Gimeno I, Fuentespina E, Tur JA, Pons A. Influence of vitamin C diet supplementation on endogenous antioxidant defenses during exhaustive exercise. Pflugers Arch. 2003; 446(6):658-64.

26. Southorn PA, Powins G. Free radicals in medicine. Chem Nat Biol React. 1988; 63(4):381-89.

Recebido em: 18/8/2009

Versão final reapresentada em: 30/11/2010 Aprovado em: 4/1/2011 